[Research Paper]

\author{
공동주택 화재를 대상으로 한 가상현실(VR) 프로그램 개발 및 호응도 조사 \\ 김용철·정무헌 ${ }^{* \dagger} \cdot$ 류 충 $^{* *} \cdot$ 김선규 ${ }^{* *}$ \\ 숭실사이버대학교 소방방재학과 외래교수, "한국소방안전원 정책연구소 선임연구원, ${ }^{* *}$ 한국소방산업기술원 기획관리이사 \\ ***한국소방안전원 감사실장
}

\title{
Development and Review of Virtual Reality Fire-Training Program
}

\author{
Yong-Cheol Kim $\cdot \mathrm{Mu}-$ Heon Jeong ${ }^{* \dagger} \cdot$ Chung Lyu $^{* *} \cdot$ Sun-Gyu Kim ${ }^{* *}$ \\ Adjunct Professor, Dept. of Fire \& Disaster Prevention, Korea Soongsil Cyber Univ., \\ ${ }^{*}$ Senior Researcher, Policy Research Institute, Korea Fire Safety Institute, \\ ${ }^{* *}$ Planning \& Management Director, Korea Fire Institute, \\ ${ }^{* * *}$ General Manager, Internal Auditing Division, Korea Fire Safety Institute.
}

(Received September 24, 2019; Revised November 4, 2019; Accepted November 20, 2019)

\section{요 약}

본 연구는 최근 빈번하게 발생하고 있는 공동주택 화재로 인한 인명피해 최소화를 위해 최신 IT 기법을 활용하여 공동주택(아파트)의 화재 상황을 재현 한 가상현실(VR) 화재 프로그램을 개발하고 학습도구로서의 활용가능성을 검 증하였다. 이를 위해 공동주택 단위평면 크기, 가족구성 등 기본환경을 설정하였으며 공동주택에서 일어날 수 있는 화재 시나리오를 개발하여 게임형식으로 가상현실 프로그램을 구현하였다. 아울러 개발된 가상현실(VR) 화재 프로 그램에 대한 호응도를 살펴보기 위해 설문조사를 실시하였다. 설문결과 가상현실(VR) 화재 프로그램에 대한 호응도 가 매우 높게 나타났으며 특히 가상현실 화재 프로그램을 통한 학습효과가 높아 학습기기로서의 유효성을 확인할 수 있었다.

\section{ABSTRACT}

This study aims to minimize casualties in the event of an apartment fire by developing a virtual reality (VR) fire-training program (using the latest IT techniques) and verifying its validity as a learning tool. For this purpose, environmental parameters, such as the unit floor's size and the composition of the family, were established. Then, possible fire scenarios that could occur in the apartment building were developed and implemented in a VR setting. Finally, a survey was conducted to review the responses to the program. The results of the survey demonstrated that the responses were positive, confirming the effectiveness of the program.

Keywords : Virtual reality, Apartment building, Fire safety education, Response survey

\section{1. 서 론}

최근 몇 년간 전 세계적으로 공동주택 화재로 인해 다수 의 인명피해가 발생하고 있다. 지난 2017년 6월 영국 웨스 트런던 켄징턴 북구에 위치한 그렌펠 타워(Grenfell Tower) 화재 ${ }^{(1)}$ 및 2015년 경기도 의정부시 대봉그린아프트 화재(2) 가 대표적인 사례라 할 수 있다. 그렌펠 타워 화재의 경우 153 명의 사상자(사망 79명, 부상 74명)가 발생하였으며 대 봉그린아파트의 경우 130 명(사망 5 명, 부상 125 명)의 사상
자가 발생하였다. 또한 최근 10 년간('08 ’17) 화재발생 통 계자료에 따르면 전체 화재발생 건수(441,030건) 대비 주거 시설의 화재발생 건수는 $25.4 \%(112,244$ 건)로 높은 비율을 나타내고 있으며 전체 인명피해 발생자수(21,811명) 대비 주거시설의 인명피해 발생자수 역시 $45.9 \%(10,018$ 명 $)$ 로 전 체의 절반에 가까운 비율을 나타내고 있다(3).

이와 같이 공동주택 화재로 인해 다수의 인명피해가 발 생한 원인으로는 가연성이 높은 외장재의 사용, 건축물의 불법 증축, 소화설비의 미작동, 화재정보 전달 및 피난유도

Corresponding Author, E-Mail: majmh@kfsi.or.kr, TEL: +82-2-2671-8693, FAX: +82-2-2679-8102

(c) 2019 Korean Institute of Fire Science \& Engineering. All right reserved. 
의 미비 등이 주요 원인이라 할 수 있다. 특히 우리나라 공 동주택의 경우 가연성 외장재의 사용뿐만 아니라 건축연수 가 오래된 공동주택이 다수 존재하여 소화설비가 제대로 작동하지 않을 우려가 높고 피난 및 피난기구 사용교육 등 공동주택 거주자를 대상으로 한 안전교육이 절대적으로 부 족한 실정이다.

이러한 현실에서 공동주택 화재 시 인명피해 최소화를 위해서는 정확한 화재정보 전달을 통한 거주자의 신속한 피난행동개시가 무엇보다 중요하다. 이를 위해서는 거주자 를 대상으로 현실감 있는 화재안전 교육 및 피난훈련의 실 시가 요구되나 이러한 교육-훈련을 위해서는 장소 및 시간 에 많은 제약이 발생하는 것이 현실이다.

이에 본 연구에서는 최신 가상현실(Virtual reality, VR)기 법을 활용하여 실제 화재상황의 재현을 통해 화재상황의 현실감과 몰입감을 극대화한 공동주택 가상현실 화재 프로 그램을 개발하고 개발한 가상현실 프로그램에 대한 호응도 조사를 실시하여 가상현실 화재 프로그램이 학습효과를 가 질 수 있는지에 대해 검증한다.

구체적으로는 공동주택을 대상으로 초기소화 및 피난행 동에 관한 시나리오를 개발하고 시나리오 상황에 맞는 가 상현실 화재 프로그램을 개발한다. 아울러 개발한 프로그 램에 대해 다양한 연령층을 대상으로 한 체험교육을 실시 한 후 호응도 조사를 통해 가상현실 화재 프로그램에 대한 소방안전 학습효과를 분석하여 학습도구로서의 역할을 확 인한다.

\section{2. 선행연구 고찰 및 가상현실 프로그램 개발}

\section{1 선행연구 고찰}

가상현실(VR)은 컴퓨터에 의해 프로그램 되는 3 차원 가 상환경을 통해 인간에게 현실감 및 몰입감을 제공하는 기 술로 최근 데이터의 시각화, 시뮬레이션, 교육, 의료, 오락 등 다양한 분야에 걸쳐 폭넓게 사용되고 있다.

특히 인위적인 구현이 어려운 소방.방재분야 교육에 있 어서 가상현실을 적용할 경우 교육생이 위험에 직접 노출 되지 않으면서 다양한 시나리오에 대해 반복훈련을 경제적 으로 할 수 있는 장점을 가지고 있다(4).

이러한 장점을 바탕으로 소방대원의 훈련 프로그램뿐만 아니라 일반인을 대상으로 한 다양한 교육-훈련 시뮬레이 션이 개발되고 있으나 가상현실을 통한 교육 및 훈련의 효 과검증은 미비한 실정이다. 아울러 가상현실을 주제로 한 선행 연구의 대부분은 시뮬레이션 또는 관련 콘텐츠 개발 에 관한 연구가 대부분으로 가상현실 기법이 소방안전교육 에 미치는 학습효과분석에 관한 연구는 매우 희박한 실정 이다.

$\mathrm{Chae}^{(5)}$ 는 가상현실을 적용한 소방교육·훈련에 관한 연구 에서 현직 소방대원들을 대상으로 재난관리 단계별 소방학 교 교육과정을 가상현실 프로그램 특성과 연관성을 고려하
여 분류한 후 AHP분석을 통하여 가상훈련 소방교육훈련 프로그램의 우선순위를 제시하였다. 이를 통해 가상현실 소방교육훈련의 도입·운영에 있어서 어떤 교육훈련이 우선 적으로 기획되어야 하는지를 확인 한 결과 대응단계와 관 련된 교육훈련을 가장 중점적으로 추진하되 '안전교육', '자원확보', '화재'와 관련된 프로그램이 우선도입 되어야 함을 강조하였다.

$\mathrm{Kwon}^{(6)}$ 은 실감가상현실을 활용한 경험학습 게임 콘텐츠 개발 및 평가에 대한 연구를 통해 가상환경 기술을 활용한 경험학습 구현 가능성을 검증하였다. 가상환경 안에서 경 험학습이 가능한지 알아보기 위해 실제 공간에서의 경험학 습과 가상의 공간에서 모사된 경험학습 간 비교를 통해 경 험의 인식에 대한 정도와 학습효과를 분석하였다. 그 결과 가상환경 기술의 생생함과 상호작용이 계속 발전하여 현실 감과 경험성이 꾸준히 향상된다면 궁극적으로 가상공간 안 에서 실제와 유사한 경험을 통해 학습하는 것이 가능함을 검증하였다.

$\mathrm{Chung}^{(7)}$ 은 UX 디자인 방법론을 적용한 VR 소방체험 교 육콘텐츠 개발에 관한 연구를 통해 현재의 안전체험교육의 문제점을 지적한 후 효과적인 해결 방안으로 VR 소방안전 체험 교육콘텐츠를 제안하였다. 소방안전체험교육 내용은 크게 소방체험(소방차 출동훈련, 소화기 사용법 등)과 안 전·대피체험(지하철 대피, 소화기 사용법 등)으로 구성되는 행동체험 학습 콘텐츠를 제시하였다. 또한 VR 소방안전체 험 교육콘텐츠는 효과적인 소방훈련과 체험을 제공할 수 있으며 소방교육의 필요충분조건인 현장감 있는 소방체험 교육, 안전한 환경제공, 학습효과를 유도하는 흥미유발, 운 영상의 비용절감을 통해 학생들의 안전체험교육 기능을 향 상시킬 수 있음을 강조하였다.

이상과 같이 가상현실을 주제로 한 소방분야 선행연구 는 가상현실의 교육현장 도입 가능성 및 활용성에 중점을 둔 연구가 대부분이다.

이에 본 연구에서는 소방안전 교육을 위한 가상현실 화 재프로그램의 개발뿐만 아니라 가상현실 화재 프로그램에 대한 호응도 조사를 통해 학습효과를 살펴본다는 점에서 기존 연구와 대비된다 할 수 있다.

\section{2 공동주택 소방안전교육 시나리오의 개발}

공동주택 화재 시 초기소화 및 피난행동에 대한 소방교 육용 시나리오 개발을 위한 환경설정으로 (1) 기존 공동주택 평면 크기 및 가족 구성, (2) 화원 및 대피시간의 선정, (3) 대 피경로의 선정 (4) 화재시나리오 등에 대해 검토하였다.

(1) 공동주택 평면 크기의 경우 국토교통부 통계누리 자 료에 따르면('16 ' 17 ) $66 \sim 115.4 \mathrm{~m}^{2}$ 의 크기가 전체의 $66.4 \%$ 를 차지하여 $99 \mathrm{~m}^{2}$ (약 30 평)크기의 평면을 기본평면 으로 선정하였다. 아울러 통계청 가구원수별 평균 가구원 수를 기준으로('15 '17) 1 인 가구 및 2 인 가구의 비율이 전체의 약 $54 \%$ 비율을 차지하나 아이를 포함한 3 인 가족 
Table 1. Composition of Scenario

\begin{tabular}{c|c|c}
\hline Sortation & Unit floor fire & Extra-unit floor fire \\
\hline \hline Initial fire & $\begin{array}{c}\text { Fire outbreak } \\
\text { (fire evolution) }\end{array}$ & $\begin{array}{c}\text { Fire in the lower floor } \\
\text { (evacuation through the front door) }\end{array}$ \\
\hline \multirow{2}{*}{ Growing fire } & $\begin{array}{c}\text { Spread of fire to kitchen } \\
\text { (fire evolution / front door evacuation) }\end{array}$ & $\begin{array}{c}\text { Smoke diffusion } \\
\text { (lightweight partition or elevator-type escape } \\
\text { apparatus) }\end{array}$ \\
\cline { 2 - 3 } After growing fire & $\begin{array}{c}\text { Spread of fire to living room } \\
\text { (lightweight partition, elevator-type escape } \\
\text { apparatus, evacuation space) }\end{array}$ \\
\hline
\end{tabular}

이상을 기준으로 했을 경우 3 인가족의 비율이 가장 높아 $(21.3 \%)$ 가족구성은 3 인으로 설정 하였다.

(2) 화원 및 대피시간 설정의 경우 주요발화요인 현황을 살펴보면 최근 10 년간('08 ’17) 전체 화재건수(441,030건) 중 부주의로 인한 화재가 $49 \%(215,249$ 건)으로 가장 높게 나타났으며 주거시설의 경우(전체 11,765 건 / ' 17 년 기준) 주방에서 발생한 비율이 $29.2 \%(3,433$ 건)로 가장 높게 나타 났다(3). 따라서 화원의 설정은 주방 가스레인지에서 부주의 로 인해 최초 발화하는 것으로 설정하였다.

대피시간의 경우 행정안전부 연구자료 ${ }^{(8)}$ 를 근거로 하여 공동주택(25층 기준) 피난의 경우 스프링클러설치 유무에 따라 최소 $200 \mathrm{~s}$ 에서 최대 $900 \mathrm{~s}$ (기준층 피난 기준)의 시간 이 필요하므로 본 연구에서는 최소 기준보다 100 초 많은 300 초(5분)를 피난에 필요한 시간으로 설정하였다.

(3) 대피경로 선정의 경우 일반적으로 공동주택에서 채 택하고 있는 대피경로(현관문을 통해 피난계단으로 피난) 를 주요 피난경로로 설정하였으나 세대 간 피난용 경계벽 (파괴하기 쉬운 경량구조), 승강식 피난기구, 대피공간 등 이 설치된 경우에는 이러한 시설들을 사용하여 피난하는 것이 가능하도록 기본 조건들을 설정하였다.

(4) 화재시나리오 개발은 발화지점, 화세강도, 대피경로, 화재 시 소화기 등의 대응 자원을 고려하여 개발하였다. 먼 저 발화지점에 대해서는 공동주택의 세대 내 주방에서 화 재가 발생한 경우와 세대외부(아랫집)에서 발생한 경우로 구분하여 시나리오를 구성하였다. 여기에 화재의 진척상황 에 따라 초기화재, 성장기 화재, 성장기 이후 화재로 구분 하였고 대피 수단에 따라 대피공간, 경량칸막이, 승강식피 난기 등의 사용가능성을 고려하였다.

가상현실 화재 프로그램 체험자는 세대내부에서 화재가 발생한 경우 119 신고 후 소화기로 초기 진화를 시도한다. 그러나 화재가 성장하여 소화가 불가능할 경우 현관 및 경 량칸막이, 승강식피난기 등을 통해 피난하는 것으로 시나 리오를 설정하였다. 만약 화재가 성장기 화재로 현관까지 확대될 때까지 피난을 완료하지 못한 경우는 방문을 폐쇄 하고 119 에 구조를 요청한 후 소방대원의 구조를 기다리는 시나리오로 설정하였다.
세대외부인 아랫집에서 화재가 발생한 경우에는 연기확 산 정도에 따라 경량칸막이, 승강식피난기구, 대피공간 등 을 활용하여 피난한다. 이 때 연기가 대량으로 유입되어 더 이상 피난하지 못할 경우는 세대내부 화재의 경우와 같이 방문을 폐쇄하고 소방대원의 구조를 기다리는 내용으로 시 나리오를 구성하였다. 시나리오 구성 및 주요내용(소화활 동 및 피난행동)은 다음의 Table 1과 같다.

\section{3 가상현실 화재 프로그램 개발}

가상현실(VR) 화재 프로그램의 하드웨어 구성은 $\mathrm{PC}$, 모 니터, Head Mounted Display (HMD), Game-pad로 구성된다. $\mathrm{PC}$ 는 그래픽이 원활하게 구현될 수 있는 성능의 $\mathrm{PC}$ 이며 $\mathrm{HMD}$ 는 오큘러스 리프트(Oculus DK2)를 사용하였다. 작동 은 조이스틱, 마우스, 키보드를 다 사용할 수 있도록 구현 하였다.

가상현실 화재 프로그램의 소프트웨어측면의 구성은 공 동주택에서 일어날 수 있는 화재시나리오에 근거하여 공동 주택 평면, 가족구성, 화원설정, 소화기구, 대피경로 등으로 구성하였다. 가상현실 화재 프로그램의 진행 방법은 게임 형태로서 시나리오에 근거하여 각각의 스테이지를 체험자 스스로가 선택하여 반복체험을 실시할 수 있도록 구성하였 다. 이때 화재 프로그램을 게임형태로 적용한 이유는 체험 자의 재미를 극대화하여 체험을 장려하고 이를 통해 학습 효과를 높이기 위함이다.

각각의 스테이지는 다음의 Figure 1 과 같다. 스테이지 1 은 아래층에서 화재가 발생하여 연기가 올라오는 상황이며 스테이지 2는 세대 내 주방의 가스레인지에서 초기 화재가 발생한 상황이다. 스테이지 3은 세대 내 가스레인지에서 화재가 발생하여 주방까지 확산된 상황을 나타내며 스테이 지 4는 화재가 거실까지 확대되는 상황이다. 스테이지 5 는 거실까지 화재가 이미 확대된 상황이며 마지막 스테이지 6 은 화재가 이미 확대되어 침실까지 연기가 들어오는 상황 으로 구성하였다.

가상현실 화재 프로그램은 각각의 스테이지 상황에 따 라 화재신고, 초기소화, 피난행동 개시 등의 상황별 소방 교육에 맞는 내용 전개로 구성하였으며 화재신고 및 초기 


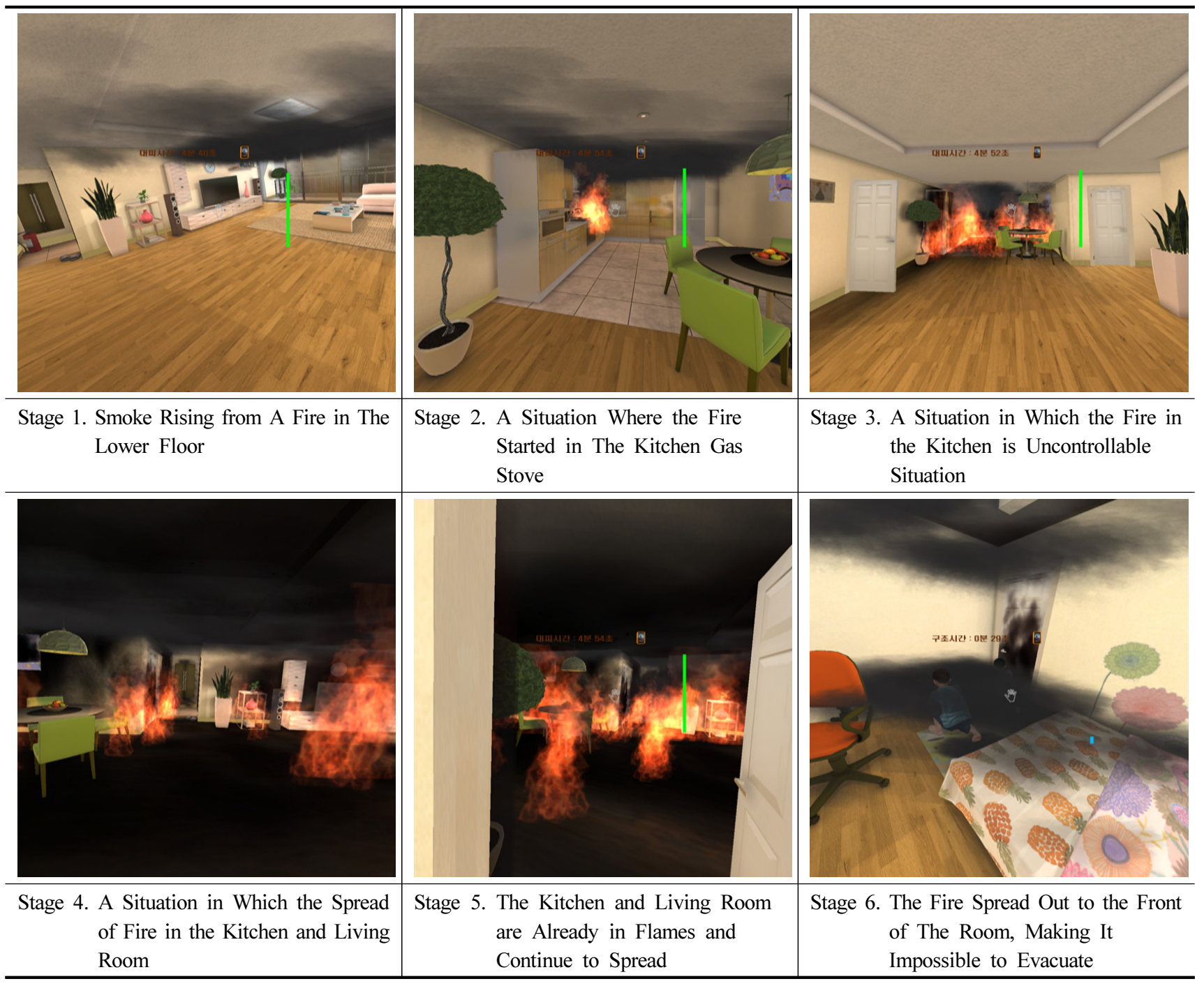

Figure 1. Configure simulation Stage 1 Stage 6 .

소화 교육을 위해 핸드폰 및 소화기, 소화전 등 UI설계를 통해 직접적인 화재신고 및 소화훈련이 가능하도록 설계하 였다.

또한 시나리오는 게임형식을 빌어 공동주택 대피시간(5 분)내에 교육자가 화재신고, 초기소화, 피난행동 등 일련의 행동을 완수하지 못할 경우 스테이지 실패로 판정하여 다 음 스테이지로 진행할 수 없도록 하였다. 아울러 화재현장 에서의 유독가스로 인한 체력저하 및 시야확보가 곤란한 점 등을 반영하여 화재상황의 전개에 따라 교육생의 생명 력이 떨어지도록 설정하였고 생명력이 떨어지기 전에 피난 행동을 완료해야 하는 긴박감을 주어 교육생의 교육 몰입 도를 높일 수 있도록 설계하였다.

Figure 1 에서 스테이지 $1,2,3$ 의 중간 우측 부분에 녹색 바(Bar)가 표시되는데 이것이 생명력에 대한 표시이며 시 간이 지남에 따라 녹색 바(Bar)가 줄어들어 스테이지내에 서 주어진 행동의 완수여부를 결정하게 되는 조건으로 설 정하였다.
시뮬레이션의 UI 및 소방안전 교육 내용은 다음의 Figure 2와 같이 소화기, 휴대폰, 옥내소화전, 경량칸막이, 승강식피난기 등이 구현되었다.

\section{3. 가상현실 화재 프로그램에 대한 호응도 조사}

\section{1 설문지의 구성}

가상현실(VR) 화재 프로그램에 대한 호응도 조사를 위 해 체험 참여자를 대상으로 한 설문조사를 실시하였다. 설 문조사는 지난 국제소방안전박람회(대구광역시 주최) 기간 중 한국소방안전원의 홍보부스를 방문한 관람객을 대상으 로 가상현실을 활용한 화재안전체험 교육을 실시한 후 호 응도에 대한 의견을 수렴하였다. 설문지는 가상현실의 현 실감, 체험자와의 상호작용 정도, 체험자의 즐거움, 교육의 전문성, 교육 학습효과의 5 개 분야로 구분하였으며 전체 문항 수는 총 10 문항(Appendix 참조)으로 구성하였다.

설문문항 중 '현실감'의 경우 가상현실이 화재상황을 얼 


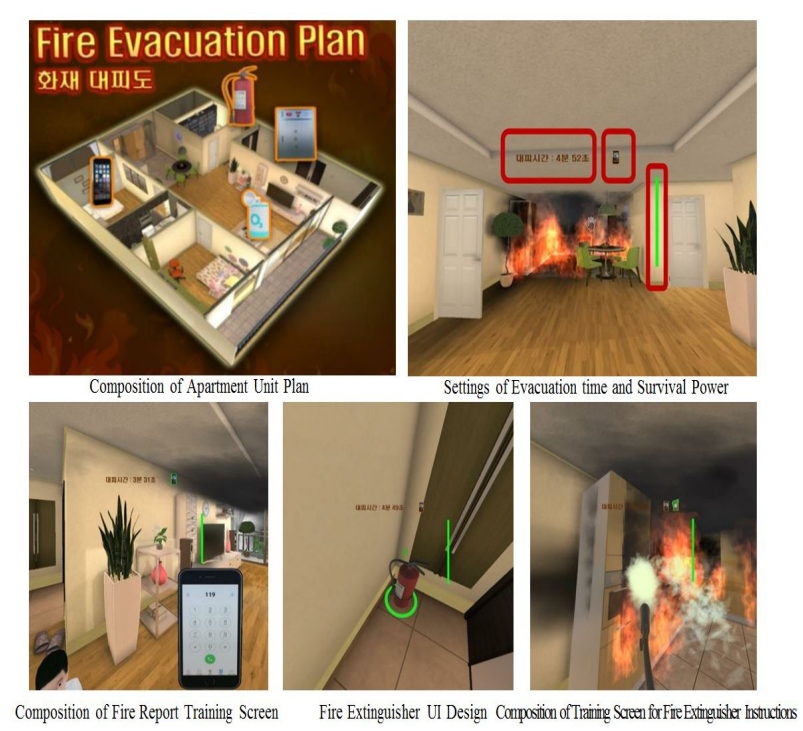

Figure 2. Configure simulation UI and firefighting training contents.

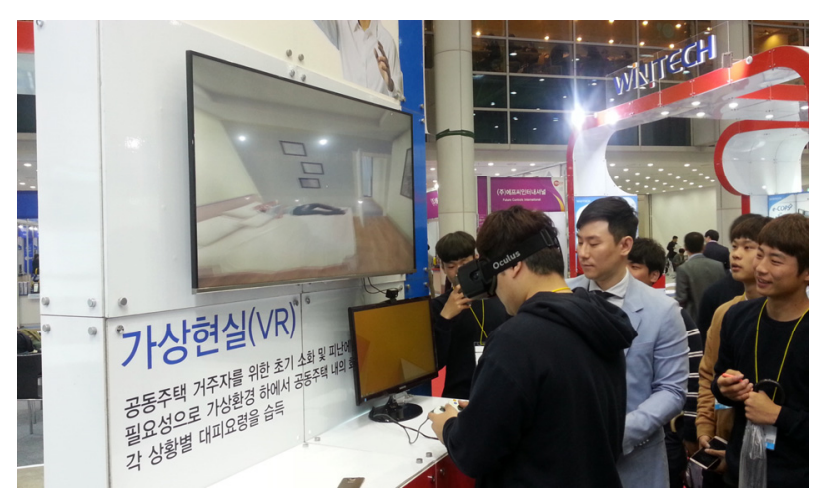

Figure 3. Image of fire safety education using virtual reality.

마나 현실적으로 반영했는지를 검증하기 위한 문항으로 구 성하였으며 '상호작용'은 가상현실 프로그램 사용의 친숙
한 정도를 묻는 문항으로 구성하였다. 교육의 ‘전문성'을 묻는 문항은 가상현실 프로그램이 소방안전 지식의 반영정 도를 확인하는 문항으로 구성하였으며 ‘즐거움'은 가상현 실 프로그램을 체험하는 동안의 즐거움을 묻는 항목으로 구성하였다. '학습효과'는 가상현실 프로그램이 화재소화 및 피난 등에 대한 지식을 측정할 수 있는 방법으로 유효 한지 여부와 화재소화 및 피난 능력 향상에 도움이 되었는 지 확인하는 문항으로 구성하였다.

\section{2 가상현실 화재 프로그램에 대한 호응도 조사}

가상현실(VR)을 활용한 화재 프로그램에 대한 호응도 조사는 한국소방안전원 홍보부스를 방문한 약 500 명 중 교 육에 참여한 100 명을 대상으로 실시하였다. 호응도 조사는 대상자들에게 가상현실 프로그램의 개요 및 조작법 등을 설명하고 스테이지 별로 직접 체험하는 방식으로 진행하였 으며 1 인당 체험시간은 평균 약 5 분정도 소요되었다. 가상 현실 화재 프로그램 체험의 모습은 Figure 3과 같다.

전체 체험자는 100 명이였으나 설문에 불성실하게 응답 한 3명은 분석에서 제외하였다. 이에 분석대상은 총 97 명 으로 남성 참여자가 74 명(76\%), 여성 참여자가 23 명 $(24 \%)$ 으로 나타났다. 평균연령은 25.3세이며, 학력은 대졸이 49 명 $(51 \%)$ 으로 가장 높게 나타났다.

가상현실 화재 프로그램에 대한 호응도 조사에 대한 빈도 분석 결과는 Table 2에서 보듯이 각각의 항목에 대한 평균은 매우 그렇다 $(48.7 \%)$, 그렇다 $(31.8 \%)$, 보통이다(13.1\%), 그렇 지 않다(3.4\%), 매우 그렇지 않다 $(0.9 \%)$ 로 나타났다. 이는 가상현실을 이용한 공동주택 화재 프로그램이 체험자들에 게 전반적으로 호응도가 높음을 의미할 뿐만 아니라 즐거 움에 대한 긍정적인 답변(73\%) 또한 높게 나타나 게임형식 을 통한 소방안전 교육의 가능성을 확인하였다. 아울러 학 습효과에 대해서는 $89 \%$ 가 긍정적인 답변을 보여주어 학습 기기로서의 유효함도 확인하였다.

Table 2. Response Survey Result

\begin{tabular}{|c|c|c|c|c|c|c|c|c|c|c|c|c|c|c|c|c|}
\hline \multirow{2}{*}{ Sortation } & \multicolumn{3}{|c|}{ Reality } & \multicolumn{3}{|c|}{ Interaction } & \multicolumn{3}{|c|}{ Professionalism } & \multicolumn{3}{|c|}{ Joy } & \multicolumn{3}{|c|}{ Learning effect } & \multirow{2}{*}{$\begin{array}{c}\text { Total } \\
\text { sum } \\
(\%)\end{array}$} \\
\hline & (1) & (2) & $\begin{array}{l}\text { sum } \\
(\%)\end{array}$ & (1) & (2) & $\begin{array}{l}\text { sum } \\
(\%)\end{array}$ & (1) & (2) & $\begin{array}{l}\text { sum } \\
(\%)\end{array}$ & (1) & (2) & $\begin{array}{l}\text { sum } \\
(\%)\end{array}$ & (1) & (2) & $\begin{array}{l}\text { sum } \\
(\%)\end{array}$ & \\
\hline $\begin{array}{c}\text { Very } \\
\text { Satisfied }\end{array}$ & 29 & 51 & 40 & 46 & 60 & 53 & 39 & 48 & 43.5 & 39 & 37 & 38 & 61 & 77 & 69 & 48.7 \\
\hline $\begin{array}{c}\text { Somewhat } \\
\text { Satisfied }\end{array}$ & 46 & 30 & 38 & 34 & 28 & 31 & 40 & 30 & 35 & 35 & 35 & 35 & 28 & 12 & 20 & 31.8 \\
\hline Neutral & 20 & 11 & 15.5 & 12 & 6 & 9 & 16 & 17 & 16.5 & 18 & 21 & 19.5 & 5 & 5 & 5 & 13.1 \\
\hline $\begin{array}{l}\text { Somewhat } \\
\text { Dissatisfied }\end{array}$ & 2 & 3 & 2.5 & 4 & 1 & 2.5 & 2 & 1 & 1.5 & 5 & 4 & 4.5 & 2 & 1 & 1.5 & 2.5 \\
\hline $\begin{array}{c}\text { Very } \\
\text { Dissatisfied }\end{array}$ & 0 & 2 & 1 & 1 & 2 & 1.5 & 0 & 1 & 0.5 & 0 & 0 & 0 & 1 & 2 & 1.5 & 0.9 \\
\hline
\end{tabular}




\section{4. 결 론}

본 연구는 최근 빈번하게 발생하고 있는 공동주택 화재 로 인한 인명피해 최소화를 위해 최신 IT기법을 활용한 가 상현실(VR) 화재 프로그램을 개발하고 이에 대한 호응도 조사를 통해 학습효과 및 학습기기로서의 유효성을 검증하 였다.

구체적으로는 공동주택 단위세대 평면의 크기, 가족구 성, 화원 및 대피시간, 대피경로 등을 기본 환경으로 설정 하였으며 소방안전 교육을 위한 화재 시나리오를 단위세대 내부와 외부에서 화재가 발생한 경우로 구분하여 시나리오 를 개발 하였다.

가상현실 화재 프로그램의 경우 화재신고를 위한 핸드 폰 및 초기소화를 위한 소화기, 소화전, 승강식피난기구 등 의 다양한 UI 설계를 통해 화재신고 및 초기소화 훈련이 가능하도록 프로그램을 설계하였다.

또한 화재상황의 전개에 따라 총 6 개의 스테이지로 교육 내용을 구분하고 교육생 스스로가 교육내용을 선정하여 반 복적인 교육이 가능하도록 가상현실 화재 프로그램을 개발 하였다.

이를 바탕으로 가상현실을 이용한 화재 프로그램 체험 교육 및 호응도 조사를 실시하였고 조사결과 전체 평균 $80.5 \%$ 가 긍정 답변을 나타내어 높은 호응도를 가지는 것으 로 분석되었다. 이를 통해 가상현실 화재 프로그램이 소방. 방재분야 교육용 기자재로서의 가치를 가질 수 있음을 증 명하였다는 점에서 연구의 의의를 가지고 있다.

이에 향후 연구에서는 공동주택 이외의 다양한 특정소 방대상물을 대상으로 한 가상현실 화재 프로그램을 개발하 고 교육효과를 증명한다면 가상현실 프로그램은 소방.방재 분야의 교육기법으로서의 유용성은 더욱 높아질 것이다.

\section{후 기}

본 연구는 한국소방안전원의 지원을 받아 수행되었으며 관계제위께 감사드립니다.

\section{References}

1. https://news.joins.com/article/21794541

2. http://news.khan.co.kr/kh_news/khan_art_view.html? art_id=201501102040411

3. https://nfds.go.kr

4. D. M. Kim and K. H. Kim, "The Current Status of Augmented Reality and Virtual Reality Experience", Proceedings of 2016 Annual Conference, The Society of Disaster Information, pp. 138-142 (2016).

5. J. Chae, "Study on Firefighting Education and Training Applying Virtual Reality", Fire Science and Engineering, Vol. 32, No. 1, pp. 108-115 (2018).

6. C. S. Kwon, "A Study on Development and Evaluation of Experiential Learning Game Content Using Authentic Virtual Reality", Doctoral Dissertation, Seoul National University (2017).

7. Y. K. Chung, "Development of VR Fire-extinguishing Experience Education Contents Using UX Design Methodology", The Journal of the Korea Contents Association, Vol. 17, No. 3, pp. 222-230 (217).

8. Korean Institute of Fire Science \& Engineering, "Development of Fire Prevention and Suppression Measures for High-rise Buildings", pp. 108-116 (2006).

Appendix : Questionnaire

\begin{tabular}{|c|c|c|c|c|c|c|}
\hline No. & Question & \multicolumn{5}{|c|}{ Answer } \\
\hline 1 & How realistic do you think the fire situation is in this virtual reality experience? & (1) & (2) & (3) & (4) & (5) \\
\hline 2 & How impressive was this virtual reality experience? & (1) & (2) & (3) & (4) & (5) \\
\hline 3 & Was this virtual reality experience familiar and easy to use? & (1) & (2) & (3) & (4) & (5) \\
\hline 4 & Did this virtual reality experience accelerate your learning experience? & (1) & (2) & (3) & (4) & (5) \\
\hline 5 & Was it a pleasant experience compared to the existing learning experience? & (1) & (2) & (3) & (4) & (5) \\
\hline 6 & How educationally interesting was this virtual reality experience? & (1) & (2) & (3) & (4) & (5) \\
\hline 7 & How do you think this virtual reality experience reflected the knowledge of evacuation? & (1) & (2) & (3) & (4) & (5) \\
\hline 8 & Do you think this virtual reality experience can measure your fire evacuation knowledge in each step? & (1) & (2) & (3) & (4) & (5) \\
\hline 9 & Have you improved your fire evacuation skills after experiencing this virtual reality? & (1) & (2) & (3) & (4) & (5) \\
\hline 10 & Did this virtual reality experience help you to improve your fire escape capability? & (1) & (2) & (3) & (4) & (5) \\
\hline
\end{tabular}

※ (1) : Very Satisfied, (2) : Somewhat Satisfied, (3) : Neutral, (4) : Somewhat Dissatisfied, (5) : Very Dissatisfied 